\title{
Fall in admission rate of old people to psychiatric units
}

\author{
K SHULMAN, TOM ARIE
}

British Medical fournal, 1978, 1, 156-158

\section{Summary and conclusions}

The numbers of the elderly, and particularly the very old, have been increasing and continue to increase rapidly; but admission rates of old people to psychiatric hospitals in England and Wales suddenly started to fall in 1970. They were still generally falling in 1974 (the most recent year for which figures are available). There is no evidence that the incidence of dementia has suddenly fallen, or that expansion of extramural or other nonpsychiatric services is everywhere coping with the severely demented.

It is probably becoming more difficult for demented people to be admitted to psychiatric hospitals that are often still overcrowded, in view of the greater scrutiny of institutional care that has become established since the Ely Report of 1969. If this is so the cost to the demented and those who care for them of the undoubted improvements in conditions in psychiatric hospitals needs to be counted.

\section{Introduction}

The number and proportion of the elderly and particularly the very old are rising rapidly. ${ }^{1}$ The pressures on psychiatric and

TABLE I-Admission rates of patients aged 65 and over to mental illness hospitals and units and teaching hospitals, 1964-74. Rates per 100000 populations aged 65 and over for England and Wales

\begin{tabular}{c|c|c|c|c|c|c}
\hline & \multicolumn{3}{|c|}{ All admissions } & \multicolumn{3}{|c|}{ First admissions* } \\
\cline { 2 - 7 } & Total & Men & Women & Total & Men & Women \\
\hline 1964 & 561 & 492 & 602 & 343 & 321 & 356 \\
1965 & 561 & 488 & 606 & 352 & 319 & 372 \\
1966 & 576 & 506 & 619 & 358 & 327 & 377 \\
1967 & 557 & 474 & 608 & 340 & 301 & 364 \\
1968 & 578 & 500 & 626 & 358 & 325 & 378 \\
1969 & 591 & 509 & 641 & 363 & 327 & 385 \\
1970 & 581 & 504 & 628 & 269 & 254 & 279 \\
1971 & 567 & 480 & 621 & 253 & 228 & 268 \\
1972 & 567 & 472 & 625 & 241 & 214 & 257 \\
1973 & 557 & 448 & 626 & 231 & 201 & 250 \\
1974 & 549 & 442 & 617 & 225 & 196 & 242 \\
\hline
\end{tabular}

*From 1970 first admissions were determined by a different method (see text), indicated by italic numbers.

Goodmayes Hospital, Ilford, Essex

K SHULMAN, MD, Ontario Mental Health Foundation fellow (present address: Maudsley Hospital, London SE5)

TOM ARIE, FRCPSYCH, FFCM, consultant psychiatrist (present address:

Professor of Health Care of the Elderly, Queen's Medical Centre,

Nottingham NG7 2UH)

other services caused by this increase are familiar: people aged 75 years and over have by far the highest admission rates to psychiatric units of any age group. It is all the more puzzling therefore that in 1970 the trend of the admission of old people (65 and over) to psychiatric hospitals and units unexpectedly changed.

During 1969-74 there was no great change in admission rates for all ages (in fact, there was a minimal upward trend). But in 1970 the upward trend in the rate of "all admissions" (table I) for the 65-and-over age group reversed, though the actual number of admissions rose slightly. For all patients with a diagnosis of senile or presenile dementia the fall in rate between 1969 and 1970 was so pronounced that even the numbers of admissions for this category fell and continued to fall steadily up to 1973 , with a minimal increase in numbers (but not rates) in 1974 (table II). In this paper, arguing that this is not an artefact, we consider the possible causes and the type of data needed for reaching firm conclusions about them.

\section{First-admission rates}

First-admission rates fell by $12 \%$ from 1970 to 1974 for all ages, but for the 65 -and-over group they fell by $17 \%$ (fig 1); the fall in firstadmission rates for senile or presenile dementia in over-75s from 1970 to 1974 was $25 \%$ (fig 2). The fall in first-admission rates of the elderly occurred right acrose England and Wales (table III). For the 65-74 age group the fall from 1970 to 1973 ranged from $15 \%$ in the Southwestern region to $51 \%$ in the Birmingham region, and for the over-75s from $4 \%$ in the South-east Metropolitan region to $49 \%$ in the Birmingham region; there have thus been large regional variations, but no region has seen an upward trend. ${ }^{3}$

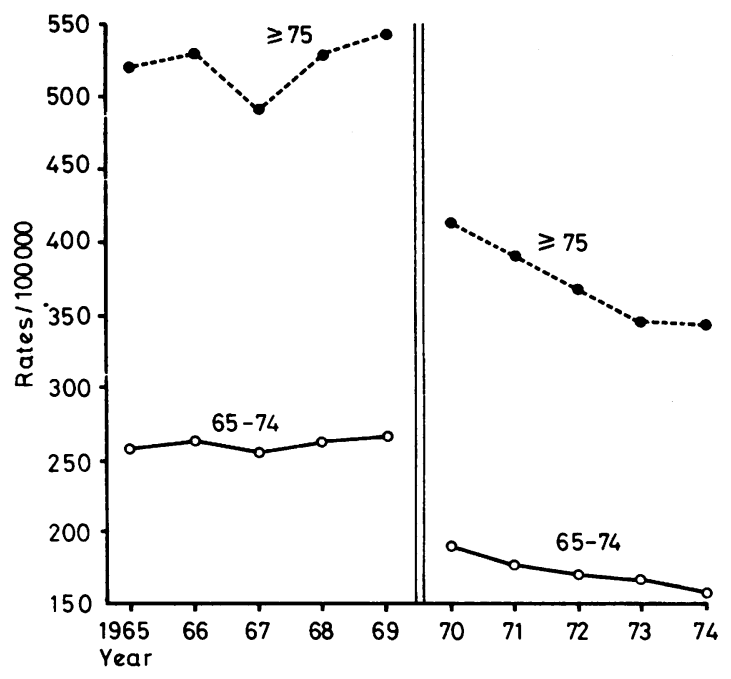

FIG 1-First-admission rates for all diagnoses, England and Wales. 
TABLE II-Senile and presenile dementia: all and first admissions in England, 1965-74

\begin{tabular}{|c|c|c|c|c|c|c|c|c|c|c|}
\hline & 1965 & 1966 & 1967 & 1968 & 1969 & 1970 & 1971 & 1972 & 1973 & 1974 \\
\hline $\begin{array}{l}\text { All admissions } \\
\text { First admissions* }\end{array}$ & $\begin{array}{r}12164 \\
9149\end{array}$ & $\begin{array}{r}12244 \\
9215\end{array}$ & $\begin{array}{r}11483 \\
8567\end{array}$ & $\begin{array}{r}12223 \\
9115\end{array}$ & $\begin{array}{r}11958 \\
8777\end{array}$ & $\begin{array}{rl}10 & 336 \\
6 & 146\end{array}$ & $\begin{array}{l}9646 \\
5667\end{array}$ & $\begin{array}{ll}9 & 156 \\
5 & 114\end{array}$ & $\begin{array}{l}9030 \\
4706\end{array}$ & $\begin{array}{l}9083 \\
4827\end{array}$ \\
\hline
\end{tabular}

* See footnote to table I.

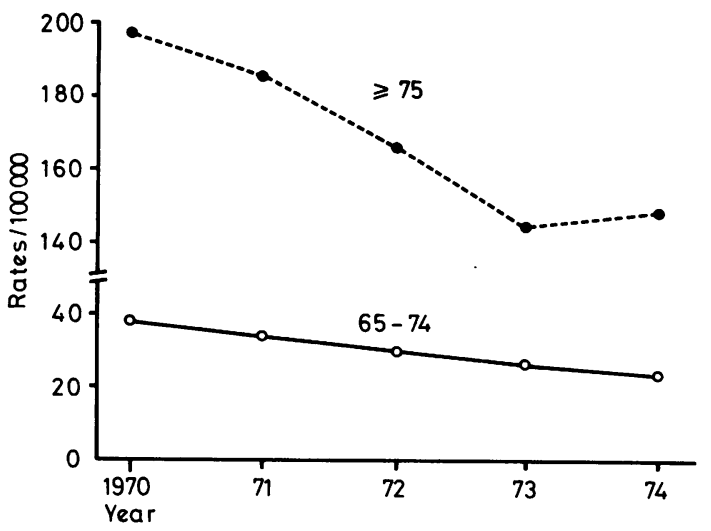

FIG 2-First-admission rates for patients with diagnosis of senile or presenile dementia, England.

TABLE III-Percentage fall in first-admission rate for senile and presenile dementia by region (England 1970-3)

\begin{tabular}{|c|c|c|c|c|}
\hline & & & $65-74$ & $\geqslant 75$ \\
\hline $\begin{array}{l}\text { England ... } \\
\text { Newcastle .. } \\
\text { Leeds } \\
\text { Sheffield .. } \\
\text { East Anglia } \\
\text { North-west Metr } \\
\text { South-east Metr } \\
\text { South-west Metr } \\
\text { North-east Metr } \\
\text { Oxford ... } \\
\text { South-western } \\
\text { Birmingham } \\
\text { Manchester } \\
\text { Liverpool .. } \\
\text { Wessex .. }\end{array}$ & 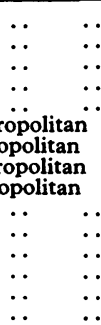 & 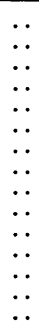 & $\begin{array}{l}33 \\
24 \\
18 \\
28 \\
17 \\
27 \\
34 \\
23 \\
32 \\
16 \\
15 \\
51 \\
50 \\
22 \\
23\end{array}$ & $\begin{array}{l}25 \\
19 \\
32 \\
30 \\
25 \\
33 \\
4 \\
30 \\
35 \\
12 \\
16 \\
49 \\
46 \\
18 \\
15\end{array}$ \\
\hline
\end{tabular}

\section{CHANGED IDENTIFICATION METHODS}

It is relevant that the method used for identifying first admissions changed in 1970, and this may have accounted for part or even all of the fall in these rates between 1969 and 1970. Before 1970 "first admissions" was applied to all patients for whom only the last spell of care had not been as an inpatient. These may have included individuals who in fact had been inpatients previously but who had subsequently been attending a day hospital or an outpatients' department. From 1970 the definition was narrowed to include only those patients who had never previously been inpatients. In its report on psychiatric hospitals and units for $1973^{2}$ the Department of Health drew attention to the fall in first-admission rates of the very elderly and suggested that psychiatrists were tending to readmit only old people who had previously been inpatients. If this explanation is valid it would mean that demented patients were less likely to be admitted, for dementia is most likely to present for the first time in later life.

The possibility exists that the first-admission rate, as defined since 1970 , may already have been falling before 1970 , but that this was hidden by the way in which first admissions were identified up to that time. But this is most unlikely, for "all admissions" (the definition of which did not change) were rising up to 1969 and then started to fall in 1970 , showing a steady downward trend to 1974 and falling by about $7.5 \%$. If the first-admission rates as now defined had in fact also been falling before 1970 one would have expected this to be reflected in the total admission rates. We think therefore that despite the change in definition of first admissions after 1969 the subsequent fall in first admissions is most unlikely to be merely an artefact, even though the size of the fall between 1969 and 1970 is probably exaggerated by the changed method of identifying first admissions. In short, for those years during the 1970s for which we have data there has been a general fall in the admission rate of elderly psychiatric patients, particularly in the first-admission rate of the elderly with dementia.

\section{Possible reasons for the falling rate}

Between the 1971 census and 1974 estimates the number of people in England and Wales aged 75 and over increased by some 130000.14 Epidemiological studies in England and Wales suggest that 10-20\% of very old people are demented, ${ }^{5}$ the prevalence increasing with age. There is therefore no reason at all to expect a fall in the admissions for dementia, let alone a sudden change of trend. Nor is there anything to suggest that the incidence of dementia in the elderly is falling, and it is quite inconceivable that it should have fallen suddenly. Changes in the functioning of services can be the only explanation, and the possibilities seem to be the following.

Improvements in community care-Investment in extramural services may have begun to pay off to the extent that demented old people are now much more likely to be adequately looked after at home. Certainly during recent years there has been a rapid increase in the number of social workers, health visitors, district nurses, home helps, and meals on wheels. ${ }^{6}$ Nevertheless, it is inherent in the nature of dementia, with its global impairments and the frequent need for constant surveillance, ${ }^{78}$ that such services, while they might be expected to improve support for those old people who can still manage at home or whose relatives can manage to look after them with support, are unlikely significantly to have diminished the number ultimately deteriorating to the point at which they will need institutional care. Moreover, surveys of mental disorder in the elderly ${ }^{8-12}$ invariably concur in showing that despite the substantial improvements that have taken place in recent years far too little help is provided.

More effective psychogeriatric services-During these years psychiatric services aimed specially at the elderly have been set up in many places. ${ }^{7}$ One service has recently claimed to have reduced admissions by intensive use of the day hospital, though others have claimed that the potential patients were merely going elsewhere. ${ }^{13} \mathrm{~A}$ more common claim about new services for the elderly is that patients have shorter spells in hospital, often with an increase in readmissions-that is, an increase in the discharge rate is the most striking consequence of new active services, and total admissions often increase.

Alternative institutional care-Between 1970 and 1974 the number of people provided with residential accommodation by local authorities or on behalf of local authorities in voluntary or private homes increased only by $7 \%$, though elderly patients in special homes for the mentally disordered increased from 14409 in 1970 to 18127 in 1974, an increase of $26 \%$ (the latter group are included within the total number of old people in residential care). ${ }^{6}$ Possibly the expansion of residential care and particularly of residential homes for the elderly mentally confused may have contributed to the fall over these years-though the rate of expansion in the previous five years was even more rapid, and during that time there had been no sign that the flow of demented old people into psychiatric hospitals was abating.

Medical geriatric units-Certainly during this period admissions to medical geriatric units have been increasing rapidly, and much more rapidly than admissions to non-psychiatric departments as a whole. Unfortunately dementia is not a diagnosis that can be reliably extracted from national data on discharges from geriatric units, since the Report of the Hospital In-Patient Enquiry ${ }^{14}$ does not primarily aim to identify mental disorders even when they are the basic cause of the admission. Between 1968 and 1973 discharges and deaths of people aged 75 and over from geriatric departments increased from 93250 to 140230 (by $51 \%$ ), the discharge rate per 10000 population of this age group rose from 423.9 to $585 \cdot 1$, and the average number of beds used daily rose from 22520 to $37474 .^{14}$ In short, (though only ad hoc studies could test the hypothesis) there may have been some shift to geriatric units of patients who normally would have been admitted to psychiatric units. At the end of 1971 government guidance was issued 
on the distribution of responsibility for the demented between geriatricians and psychiatrists, ${ }^{15}$ but this guidance, although it may have clarified the picture, reflected good existing practice rather than radical change. Moreover, any effect of this circular could not have been apparent until 1972 at the earliest.

\section{MOST PROBABLE EXPLANATION}

The likeliest explanation of the fall in admissions, and the only one that seems capable of accounting both for the suddenness of the change and for the regularity of the trend, is that psychiatrists have become increasingly reluctant to admit new elderly demented patients to their hospitals.

The time when the trend changed-1969-70-coincides with the beginning of the spate of reports of "scandals" in institutional care. 1969 saw the publication of the Ely Hospital report, ${ }^{16}$ and soon after came the report on Whittingham Hospital ${ }^{17}$; and since then a general tradition of scrutiny of long-stay institutional care has become established. The visits of the Health (formerly Hospital) Advisory Service to all psychiatric units during this time have drawn attention to overcrowding and shortages of staff and resources, and the Health Advisory Service and its Directors' annual reports ${ }^{18}$ have consistently encouraged further reduction of beds. These developments are in most respects desirable and indeed long overdue; but possibly one result has been that psychiatrists have become so concerned to avoid on the one hand crowding, with its consequences for the quality of life of both patients and staff, and on the other hand personal criticism in the face of the ever-present danger of incidents and scandals that they are often unwilling to admit elderly patients, especially those who are unlikely to leave hospital. If this is so then the cost of the general improvement of the internal environment of hospitals that has unquestionably taken place during this period may have included greater hardship for old people and their families at home.

\section{Conclusion}

While many factors may have contributed to the declining admission rate of the elderly to psychiatric hospitals, the most likely explanation seems to be a growing reluctance to admit the demented. There is no evidence of a fall either in need or in demand, though data on both are inadequate. More data would be needed, including operational studies of referrals and clinical studies of the patients referred, to elucidate the causes of this new trend, which may generate big problems as the number of the demented continues to increase. The reasons for the huge variations in admission rates between the regions particularly call for further study. Similarly, inquiries such as those carried out by Grad and Sainsbury ${ }^{19}$ and others ${ }^{20}$ in the 1960 s into the burden on families urgently need to be repeated since the pattern of services and, probably, of public expectations has changed greatly since then.

It is not enough to strive to protect our hospitals against scandals (if that is in fact what we are doing); we need also to be counting the cost for those at home. Above all no one should jump to conclusions that the demand for psychiatric hospital care for the very old is "levelling off." We have scanty information on the level of demand and of need and on referrals to psychiatrists-for instance, there are no satisfactory data on domiciliary visits. Moreover, trends in admissions of demented people to psychiatric beds give no indication of the numbers finding their way into other institutional care-as Jolley ${ }^{21}$ has recently shown, many comparable patients are found in other beds and in residential homes. In the 1960s Kay et al ${ }^{5}$ showed that six out of seven demented old people were at home, and more recently Pasker et al have found much the same. ${ }^{11}$ That most of the demented should, indeed must, continue to be cared for at home is not in question; but how many who ought to be in hospital are at home because, for lack of resources or fear of criticism, we are keeping them out ?

We gratefully acknowledge the ready help that we were given in preparing this paper by members of the staff of the mental health statistics division of the Department of Health and Social Security, but they are not of course responsible for the interpretations of the data that we have suggested.

\section{References}

1 Government Statistical Service, Population Projections, 1974-2014. London, HMSO, 1976.

2 Department of Health and Social Security, Psychiatric Hospitals and Units in England. In-Patient Statistics from the Mental Health Enquiry for the years 1973-4. London, HMSO, 1976-7.

${ }^{3}$ Department of Health and Social Security, personal communications.

4 Office of Population Censuses and Surveys, Census 1971. Great Britain Summary Tables, London, HMSO, 1973.

${ }^{5}$ Kay, D W K, Beamish, P, and Roth, M, British fournal of Psychiatry, $1964,110,146$.

6 Department of Health and Social Security, Health and Personal Social Services Statistics for England 1975. London, HMSO, 1976.

${ }^{7}$ Arie, T, in Care of the Elderly, ed A N Exton-Smith and J Grimley Evans. London, Academic Press, 1977.

${ }^{8}$ Isaacs, B, and Neville, I, British Fournal of Preventive and Social Medicine, $1976,30,79$.

9 Townsend, P, and Wedderburn, D, The Aged in the Welfare State. London, Bell, 1965.

${ }^{10}$ Harris, A, Social Welfare for the Elderly. London, HMSO, 1968.

11 Pasker, P, Thomas, J P R, and Ashley, J S A, British Medical fournal, 1976, 3, 164.

12 Opit, L J, British Medical Fournal, 1977, 1, 30

13 Baker, A A, British fournal of Psychiatry, 1977, 130, 123. Correspondence, 521.

14 Department of Health and Social Security, Report of the Hospital In-Patient Enquiry for 1973, preliminary tables. London, HMSO, 1976.

15 Department of Health and Social Security, Services for Mental Illness Related to Old Age, circular HM(72)71. London, HMSO, 1972.

${ }^{16}$ Report of the Committee of Inquiry into Allegations of Ill-Treatment of Patients and Other Irregularities at the Ely Hospital, Cardiff. Cmnd 3975. London, HMSO, 1969.

${ }^{17}$ Report of the Committee of Inquiry into Whittingham Hospital. Cmnd 4861. London, HMSO, 1972.

18 National Health Service Hospital Advisory Service, Annual Reports, 1969-1975. London, HMSO, 1970-6.

19 Grad, J, and Sainsbury, P, in Psychiatric Disorders in the Aged. Manchester, Geigy, 1965.

${ }^{20}$ Hamilton, M W, and Hoenig, J, Medical Officer, 1966, 15, 193.

21 Jolley, D, British Medical fournal, 1977, 1, 1335.

(Accepted 27 October 1977)

A 65-year-old man has suffered from persistent catarrh for 20 years, which he claims started after an attack of influenza. The results of investigations have proved negative, and treatment has been unavailing. What advice should he be given?

This is a relatively common condition: one that is trying both to the patient and for his doctor because of the difficulties in finding any causes and any effective treatments. Basically the condition is a vasomotor rhinitis, where the autonomic nerves in the nasal mucosa are irritated causing an intense flow of clear secretions. The initial stimulus that triggers off this reflex irritation may be one of many sorts-usually acute upper respiratory infections, allergies, and emotional stress. Once initiated, other factors may aggravate matterssuch as atmospheric conditions or humidities, body hormonal changes, and vascular system reactions to temperature changes. Investigations, having already excluded a persistent infection, should try to determine whether: (a) any allergic sensitivity has occurred to an infinite range of irritants-such as household mites, hyphae (in damp night air especially), and foods such as cheese, eggs, tomatoes, alcohol, tobacco, etc; $(b)$ stress or tension is an unsuspected factor (it often is); (c) there is any rise in the serum urate or blood cholesterol concentrations; or $(d)$ the patient has, or had, chilblains or other signs of peripheral vascular spasm.

For treatment a sympathetic explanation of the difficulties of doctors to explain the vagaries of the body can be helped by having trial periods on $(a)$ at least two or three of the various types of antihistamines not already tried-some work on patients much better than others; (b) small dosage of imipramine for at least six weeks or amitryptyline for one week: they appear to act on the autonomic system in the nose (I am not keen on local cortisone); or (c) calcium by mouth; there is a useful effervescent type. For no logical or scientific reasons it sometimes gives considerable relief.

${ }^{1}$ Foxen, E H M, British fournal of Clinical Practice, 1972, 26, 363. 